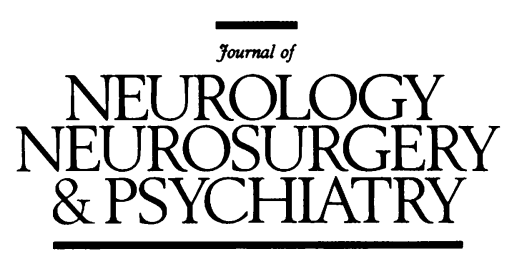

\title{
Editorial
}

\section{The inherited ataxias and the new genetics}

The powerful new tools of genetic investigation are steadily expanding our understanding of the molecular basis of inherited neurological disease. This is particularly so in the context of the inherited ataxias, in which nosological difficulties are beginning to be resolved by a genetically based classification. Harnessing the new knowledge will bring further rewards, including molecular genetic diagnosis, definition of clinical phenotypes, elucidation of pathophysiology, and the possibility of new treatments. Many metabolic disorders include ataxia as a more or less prominent feature. Traditionally it has been useful to distinguish these disorders from the "idiopathic" inherited ataxias, although the distinction is already seeming artificial as pathological mechanisms are elucidated. This review considers the impact of the new knowledge on the inherited ataxias previously considered idiopathic.

\section{Classification of the idiopathic inherited ataxias}

Although pathological study has provided insights into the anatomy and pathophysiology of the ataxias, pathologically based classifications have proved unsatisfactory when clinical features and inheritance (and recently, molecular genetic data) are not considered. With some exceptions, clinical criteria alone are also inadequate, as there may be discordance even between affected ataxic siblings in fea-

\section{Table 1 The idiopathic inherited ataxias (derived from Harding')}

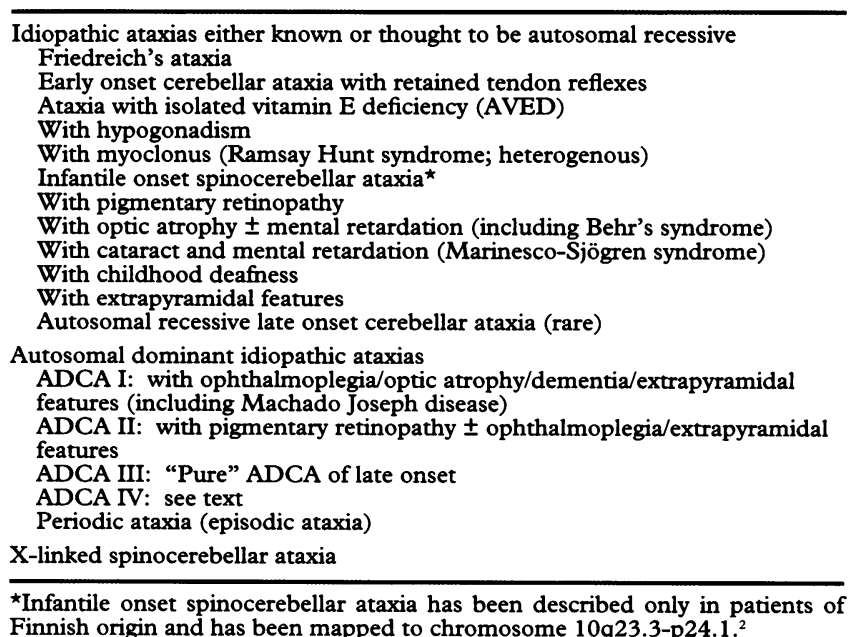

tures such as areflexia or ophthalmoplegia. Harding's classification is based on mode of inheritance together with clinical criteria (table 1 ) and is increasingly accepted. ${ }^{1}$ The principles of this classification have withstood the genetic discoveries of the past decade. This article presents the new genetic data on this framework.

\section{The autosomal recessive ataxias FRIEDREICH'S ATAXIA}

Between 1863 and 1877 Friedreich reported the distinctive clinical syndrome that was to bear his name. ${ }^{3}$ It is the commonest genetic ataxia and is of autosomal recessive inheritance, with progressive gait and limb ataxia as the cardinal features. It is associated with lower limb areflexia; dysarthria, pyramidal weakness, and sensory loss manifest later in the course of the disease. In 1981 Harding proposed diagnostic criteria (table 2 ), ${ }^{4}$ which defined a genetically homogenous group; linkage to markers on chromosome 9 was demonstrated in $1988 . .^{5}$ Further work allowed more precise localisation and identification of candidate genes. ${ }^{6-8}$ Campuzano et al recently identified one such candidate gene (X25) within the critical region on chromosome $9 .{ }^{9}$ One fragment of the gene was noticed to contain an expansion, leading to the discovery of a GAA trinucleotide repeat within intron 1 of the gene. Normal chromosomes contain 10-21 GAA repeats, but nearly $95 \%$ of Friedreich's ataxia chromosomes contained between 200 and $900 \mathrm{GAA}$ trinucleotide repeats. Of 79 unrelated patients with typical Friedreich's ataxia Campuzano et al found homozygosity for the expanded allele in 71 , and heterozygosity in the remaining eight. Five of the eight had point mutations detected within $\mathrm{X} 25$.

The X25 gene product, termed frataxin, contains 210 amino acids. The gene comprises six exons, with evidence of alternate splicing. There is no resemblance to other known genes, and as yet it is not possible to predict the function of frataxin. Northern blots show that X25 expression is high in the heart, with intermediate levels in the liver, skeletal muscle, and pancreas, and minimal levels in other tissues, including whole brain. Comparison between CNS tissues showed high expression in the spinal cord, less in the cerebellum, and very little in the cerebral cortex. Messenger RNA concentrations were undetectable or extremely low in patients with Friedreich's ataxia, suggesting that the mutation causes interference in transcription or RNA processing. Reduced frataxin in the heart and 
Table 2 Friedreich's ataxia: diagnostic criteria (derived from Harding")

Essential criteria for diagnosis

(a) Within 5 years of onset of symptoms:

Progressive ataxia of limbs and gait

Extensor plantar response

Motor nerve conduction velocity $>40 \mathrm{~m} / \mathrm{s}$ in upper limbs with small or absent sensory action potentials

Age of onset of symptoms before 25 years ${ }^{\star}$

Absent knee and ankle jerks ${ }^{\star}$

(b) After 5 years since onset of symptoms:

Dysarthria

Additional criteria: not essential for diagnosis: present in more than two thirds of cases

Scoliosis

Pyramidal weakness in lower limbs

Absent reflexes in upper limbs

Distal loss of joint position sense and vibration sense in lower limbs

Abnormal ECG

Other features: present in $50 \%$ of cases or less

Nystagmus

Optic atrophy

Optic atroph

Distal weakness and wasting

Pes cavus

*Patients without these features have shown linkage to the Friedreich's ataxi *Patients without these features have shown linkage to the Friedreich's ataxia
locus on chromosome 9. It is arguable that they should appear as "additional criteria".

A normal serum vitamin $\mathrm{E}$ should also be regarded as an essential diagnostic criterion.

spinal cord is probably the primary cause of neuronal degeneration, cardiomyopathy, and increased risk of diabetes. Although trinucleotide repeats are now familiar in autosomal dominant neurological diseases (particularly the ataxias; see below), the repeat within the frataxin gene is the first associated with an autosomal recessive disease. However, it seems to share some characteristics with previously characterised trinucleotide repeats in that the repeat is unstable, showing variation in repeat number within an individual subject as well as on transmission between generations.

The precise range of disease associated with the Friedreich's ataxia genotype will be defined in the near future by the application of direct mutational analysis. However, the use of linkage data has already provided useful information. Harding and Geoffroy et al proposed criteria excluding patients with onset after 25 and 20 years respectively, ${ }^{40}$ yet there are kindreds with later onset of disease who have otherwise similar features (late onset Friedreich's ataxia). These families are linked to the same chromosome 9 markers as in classic Friedreich's ataxia. ${ }^{1112}$ Comparison between late onset Friedreich's ataxia and classic Friedreich's ataxia showed no differences except a lower incidence of skeletal deformity and a relatively benign course, with patients with late onset Friedreich's ataxia taking five years longer than patients with Friedreich's ataxia to progress from onset to being confined to a wheelchair. Neurophysiology and neuroimaging did not differentiate between the two groups. A further interesting group are those patients who satisfy the criteria for diagnosis of Friedreich's ataxia with the exception of preserved reflexes. Studies of 11 patients from six families with the Friedreich's ataxia phenotype including cardiomyopathy, but with retained reflexes (FARR) confirmed linkage to the Friedreich's ataxia locus. ${ }^{13}$ Thus both FARR and late onset Friedreich's ataxia are likely to be allelic variants of Friedreich's ataxia. It is interesting to speculate that severity of phenotype may be related to the GAA repeat numbers within the frataxin alleles.

These data erode the value of early age of onset and areflexia as essential criteria for Friedreich's ataxia, although these features remain supportive of the diagnosis. The phenotypic range associated with the Friedreich's ataxia genotype clearly extends beyond that of classic Friedreich's ataxia given in table 2 . In clinical diagnosis, particular importance should be attached to confirmation of a sensory axonal neuropathy, which is present even in the variant FARR and late onset Friedreich's ataxia phenotypes. An ECG or echocardiogram consistent with the Friedreich's ataxia cardiomyopathy is also very helpful diagnostically, if present. ${ }^{11-13}$ Nevertheless, it is likely that some patients with the Friedreich's ataxia genotype may have neither cardiomyopathy nor severe sensory axonal neuropathy..$^{14}$ Although in many cases a confident diagnosis of Friedreich's ataxia can be made clinically, the arrival of frataxin gene mutational analysis will allow surer diagnosis of atypical patients, with implications for prognosis and genetic counselling.

OTHER AUTOSOMAL RECESSIVE ATAXIAS

Harding described a group of patients with early onset cerebellar ataxia distinguished from Friedreich's ataxia by retained reflexes (EOCARR), ${ }^{15}$ less than one quarter as common as Friedreich's ataxia. Clinically, EOCARR differs from Friedreich's ataxia not only with respect to tendon reflexes, but also because of an absence of optic atrophy, cardiac involvement, diabetes mellitus, or severe skeletal deformity. ${ }^{1516}$ However, the relation of EOCARR to FARR is not well defined, ${ }^{13}$ and some patients with EOCARR as originally described may prove to have a frataxin mutation. The absence of sensory neuropathy and MRI findings ${ }^{17}$ of cerebellar rather than spinal atrophy support the diagnosis of EOCARR. Although classification of some patients is difficult, distinction between Friedreich's ataxia and EOCARR is not trivial; patients with EOCARR have a better prognosis than that of patients with Friedreich's ataxia. ${ }^{15}$ Inheritance is thought to be autosomal recessive in most cases.

\section{ATAXIA WITH ISOLATED VITAMIN E DEFICIENCY (AVED)}

Secondary vitamin $\mathrm{E}$ deficiency (precipitated by $a \beta$ lipoproteinaemia or other fat malabsorptive syndromes) is well known to be associated with neurological manifestations including ataxia. In 1981 familial isolated vitamin $\mathrm{E}$ deficiency was first described, ${ }^{18}$ and this was followed by other reports. In these patients without gastrointestinal disturbance, onset of symptoms occurs between four and 18 years of age, with progressive ataxia, areflexia, sensory loss and pyramidal signs, and sometimes with cardiomyopathy. ${ }^{19}$ Thus AVED is a phenocopy of Friedreich's ataxia and estimation of vitamin $E$ is mandatory in all cases of suspected Friedreich's ataxia. However, although AVED is common (relative to Friedreich's ataxia) in north Africa, it seems to be relatively uncommon in northern Europe. It was linked to chromosome $8 \mathrm{q} 13$ in $1993 .{ }^{20}$ Ouahchi et al subsequently identified mutations in the $\alpha$ tocopherol transfer protein (TTP) on chromosome 8 in patients with AVED. ${ }^{21}$ Patients with AVED have an impaired ability to incorporate $\alpha$-tocopherol into lipoproteins secreted by the liver, a function attributable to the $\alpha$ TTP gene. $\alpha$-Tocopheryl acetate therapy can arrest or reverse the neurological deficit. ${ }^{22}$ One exciting possibility is that Friedreich's ataxia is a defect of vitamin E metabolism, allowing the hope of directed therapies in the future.

\section{The autosomal dominant cerebellar ataxias}

The ADCAs are heterogenous, both clinically and genetically. They have provided a nosological challenge and many different classifications have been proposed. Pure syndromes are outnumbered by those that include additional features relating to the retina, optic nerves, extrapyramidal pathways, cerebral cortex, brainstem, spinal cord, and peripheral nerve. Harding separated ADCA with pigmentary macular dystrophy (ADCA type II) from the other complicated ADCAs, which were classified as ADCA type I (table 1). ${ }^{1}$ ADCA type III denotes a 
relatively pure, usually late onset ( $>50$ years) cerebellar ataxia. Type IV indicates the additional features of deafness and neuropathy, but may no longer be a useful concept. Such families were described before mitochondrial encephalomyopathies were recognised, and might now be recognised as having the syndrome of myoclonic epilepsy with ragged red fibres (MERRF) ${ }^{24}$

\section{ADCA TYPE}

Patients typically present with a progressive cerebellar syndrome with additional features that become more frequent as the disease progresses and include supranuclear ophthalmoplegia, slow ocular saccades, optic atrophy, extrapyramidal features, mild dementia, facial, lingual, or limb fasciculation, increased or decreased tendon reflexes, and sensory loss. ${ }^{23}$ Onset may be from childhood to the eighth decade but is most common in middle life. The pathological diagnosis is usually olivopontocerebellar atrophy.

\section{The SCA1 mutation}

The first step in the genetic analysis of ADCA I was made in 1974 when linkage to HLA loci on chromosome 6 was suspected..$^{25}$ Further linkage studies established that some but not all families with ADCA were linked to the disease locus (designated SCA1) on chromosome 6 p. $^{26-29}$ A positional cloning approach culminated in the identification of an unstable trinucleotide CAG repeat sequence, ${ }^{30}$ confirmed by others. Expansion of the repeat was associated with disease; indeed there is an inverse correlation of repeat number with the age of onset of symptoms. ${ }^{31-38}$ The SCA1 trinucleotide expansion shares characteristics variably manifested in other trinucleotide repeat diseases (for example, Huntington's disease, myotonic dystrophy, $\mathrm{X}$ linked bulbospinal neuronopathy). Trinucleotide repeats are unstable, with variation in repeat number within tissues and on gametogenesis. Anticipation refers to the propensity for earlier onset and increased severity of disease in succeeding generations. Molecularly this arises from a propensity for the repeat to expand in gametogenesis. Male gametogenesis is more likely to result in repeat expansion than female gametogenesis, explaining the second finding, of severe phenotypes being more often the result of paternal transmission. In the case of SCA1, maternal transmission results in an average decrease of 0.4 repeats, whereas paternal transmission results in an average increase of 3.3 repeats. ${ }^{39}$

The SCA1 triplet has a further intriguing characteristic. The normal CAG repeat is usually imperfect; about $98 \%$ of normal alleles possess an interruption in the CAG repeat (by a CAT sequence). By contrast 30/30 disease carrying chromosomes had a perfect CAG repeat sequence. ${ }^{39}$ Repeat numbers seen on normal alleles range from 6 to 39 , and from $40-83$ on SCA1 alleles. A few cases may therefore lie close to the critical length. Present evidence suggests that a perfect expansion is more likely to indicate an SCA1 carrying chromosome. The size of the SCA1 expansion is not the sole determinant of disease; in terms of age of onset the size of the expansion has been estimated to account for $66 \%$ of the variability. ${ }^{31}$ Studying one family with a doubly interrupted repeat, ${ }^{40}$ Quan et al suggested that the specific CAG repeat configuration may be important, and warned against diagnosis on expansion size alone. Other genetic loci or environmental factors are also likely to play a part.

The CAG triplet lies within the coding region and codes for the amino acid glutamine. The messenger RNA produced from an SCAl allele is translated ${ }^{41}$; thus the CAG repeat results in a polyglutamine tract. The protein has no hydrophobic region and is probably soluble; there is no homology with previously identified proteins. Because the disease is dominant the increase in length of the polyglutamine tract must in some way result in a deleterious gain in function. Identification of the homologous murine gene showed that the CAG repeat is virtually absent in the mouse. Bursts of gene expression found in early mouse development suggested that the normal murine SCA1 gene has a role at specific stages of both cerebellar and vertebral column development. ${ }^{42}$

Robitaille et al studied 11 patients with SCA1 at necropsy, ${ }^{43}$ concluding that SCA1 was associated with a unique neuropathological phenotype characterised by severe degeneration of olivocerebellar and dentatorubral pathways, extensive loss of Purkinje cells with partial sparing of flocculonodular lobes, severe atrophy of the third and 12th cranial nerve nuclei, and extensive loss of motor neurons in anterior horns and Clarke's columns. There was relative preservation of the pars compacta nigra and locus coeruleus, and no oligodendroglial or neuronal cytoplasmic cytoskeletal inclusions.

\section{The SCA3/MFD mutation}

Machado-Joseph disease (MJD) was initially reported in people of Azorean and Portuguese descent, and has provoked a vigorous debate with respect to its classification. Whereas ataxia is usually the predominant feature, it is maintained that MJD can be distinguished clinically by the features of staring eyes, linguofacial fasciculations, and dystonia, ${ }^{44}$ and pathologically by sparing of the olives. The lumping together of many families under the rubric of ADCA I allowed Harding to include MJD in this group as the features of MJD were also seen in other ADCA I families. ${ }^{23}$

The gene locus for MJD was mapped to chromosome $14 \mathrm{q}$ in both Japanese and Portuguese families. ${ }^{45} 46$ However, the SCA3 locus was also linked to the same region in three French families with ADCA I not considered to have MJD on clinical grounds. ${ }^{47}$ The underlying mutation, common to patients with MJD or SCA3, is a CAG repeat expansion (table 3). It was first identified in Japanese patients and since in other racial groups. ${ }^{35} 3648-50$ With the knowledge that SCA3 and MJD are defined by a single mutation, it is convenient and logical to consider SCA3/MJD as one disease with varying manifestations. It is incumbent on those who would split SCA3 from MJD to justify this clinically or genetically.

Giunti and colleagues found that there was no single clinical feature that differentiated MJD or SCA3 from other ADCA type I families. ${ }^{49}$ However, it seems that the different SCA loci do have differing phenotypes (table 3), but this is manifest only when considering a group statistically, and does not allow confident individual prediction of genotype, (although racial origins may give a clue). Most patients with ADCA present with a predominantly cerebellar syndrome, but occasionally with predominantly extrapyramidal signs. The second may be more commonly seen in patients carrying the SCA3/MJD mutation ${ }^{49}{ }^{50}$; some patients receive partial benefit from levodopa. An ancestor of a family now known to carry the SCA3/MJD mutation was seen by Gowers at the National Hospital, Queen Square. The patient was initially thought to have a diagnosis of paralysis agitans. ${ }^{49}$

Interestingly there is a gap of 21 between the repeat number seen in SCA3/MJD and normal alleles (table 3), by contrast with SCA1. This may indicate a different mutational mechanism. A significant negative correlation has been found between repeat number and age at onset. ${ }^{4950}$ It is clear that there is a tendency for the repeat number to increase during transmission corresponding to the clinical phenomenon of anticipation. As seen in SCA1 
Table 3 Autosomal dominant cerebellar ataxias: a clinicogenetic classification

\begin{tabular}{|c|c|c|c|c|}
\hline Gene & Chromosome & Gene defect & Frequency* & Associated clinical features $\dagger$ \\
\hline \multicolumn{5}{|l|}{ ADCA type I } \\
\hline SCA1 & $6 \mathrm{p} 22-\mathrm{p} 23$ & $\begin{array}{l}\text { (CAG)n } \\
\text { Normal: } 6-39 \\
\text { Disease: } 41-59\end{array}$ & $\begin{array}{l}14 / 87^{31}, 5 / 19^{34}, 2 / 24^{35}, 3 / 29^{36}, 4 / 38^{37} \\
19 / 73^{38}, 13 / 120^{54} \\
\text { Overall: } 60 / 390(15 \%)\end{array}$ & $\begin{array}{l}\text { Ophthalmoplegia, pyramidal and extrapyramidal signs, } \\
\text { dementia, motor and sensory nerve involvement }\end{array}$ \\
\hline SCA2 $2^{56}$ & $12 \mathrm{q} 23-24 \cdot 1$ & - & - & $\begin{array}{l}\text { As SCA1 but more frequent hyporeflexia, supranuclear } \\
\text { ophthalmoplegia }\end{array}$ \\
\hline SCA3/MJD & $14 \mathrm{q} 32 \cdot 1$ & $\begin{array}{l}(\mathrm{CAG}) \mathrm{n} \\
\text { Normal: } 13-41 \\
\text { Disease: } 62-80\end{array}$ & $\begin{array}{l}7 / 24^{35}, 5 / 29^{36}, 19 / 38^{37}, 10 / 35^{49} \\
5 / 42^{50}, 28 / 120^{54} \\
\text { Overall: } 74 / 288(26 \%)\end{array}$ & $\begin{array}{l}\text { As SCA1 but possibly with more frequent } \\
\text { extrapyramidal signs (see text) }\end{array}$ \\
\hline $\mathrm{SCA}^{57}$ & 16q24-ter & - & - & $\begin{array}{l}\text { As SCA1 but with prominent sensory axonal } \\
\text { neuropathy }\end{array}$ \\
\hline SCA5 ${ }^{58}$ & Cent 11 & - & - & $\begin{array}{l}\text { Benign relatively pure ataxia } \\
\text { ? Harding type III }\end{array}$ \\
\hline $\begin{array}{l}\text { ADCA type } \mathrm{II}^{63,65} \\
\text { DRPLA }^{59-61}\end{array}$ & $3 \mathrm{p} 12-21 \cdot 1$ & $\bar{C}$ & - & Pigmentary macular dystrophy (see text) \\
\hline DRPLA $^{59-61}$ & $12 \mathrm{p}$ & $\begin{array}{l}(\mathrm{CAG}) \mathrm{n} \\
\text { Normal: } 8-35 \\
\text { Disease: } 54-79\end{array}$ & - & Myoclonus, chorea, epilepsy, dementia \\
\hline $\begin{array}{l}\text { Periodic ataxia } \\
\text { EA-1 } \\
\text { EA-2 }^{69}\end{array}$ & $\begin{array}{l}12 \mathrm{p} \\
19 \mathrm{p}\end{array}$ & $\begin{array}{l}\text { KCNA1 mutations } \\
-\end{array}$ & $\overline{-}$ & $\begin{array}{l}\text { Myokymia, brief attacks } \\
\text { Progressive ataxia, nystagmus, longer attacks }\end{array}$ \\
\hline
\end{tabular}

Frequencies vary according to population and with the clinical characteristics of the families surveyed-for example, SCA1 was found in $6 / 12$ British families with ADCA type I ${ }^{38}$; SCA3/MJD constituted $84 \%$ of all ADCA in Portuguese patients. ${ }^{36}$

*Frequencies are expressed as a proportion of all ADCAs studied.

tThe features of the ADCAs overlap; see text.

there is also a parental sex effect with paternal transmission showing a larger increase (about three repeats) than female transmission (about one repeat)..$^{51} 52$

At necropsy patients diagnosed as having MachadoJoseph disease have predominant involvement of the spinocerebellar tracts, Clarke's column nuclei, vestibular nuclei, and pontine base..$^{53}$ Dürr et al studied two patients with SCA1 and two patients with SCA3/MJD at necropsy. ${ }^{54}$ Whereas some features were in common they thought that the SCA3/MJD pathology could be distinguished by the presence of lesions in the internal pallidum and interomediolateral columns and lack of inferior olive and Purkinje cell degeneration.

\section{Other SCA loci}

Most ADCA I families do not carry either the SCA1 or SCA3/MJD mutations (table 3). To date three further loci have been mapped, and others are not linked to known loci. The best characterised are the SCA2 families linked to markers on chromosome $12.4^{45}$ These families show anticipation, suggesting that the mechanism underlying this disease may also be trinucleotide expansion, but no clear deleterious effect of paternal transmission has been seen. Clinically there is interfamilial and intrafamilial variation, but there is a significantly higher incidence of hyporeflexia in SCA2 families than SCA1 or SCA3 families. Neuropathologically, patients with SCA2 differ from patients with SCA3/MJD, but seem similar to patients with SCA1.56 SCA4 and SCA5 represent loci that have been assigned to chromosomes 16 and 11 by linkage analysis of single families. ${ }^{5758}$ It is not clear whether these or other undiscovered loci will account for a substantial proportion of ADCA families.

Use of a monoclonal antibody to detect polyglutamine expansions allows identification of the gene products of the Huntington protein as well as the SCA1 and SCA3/MJD gene products. ${ }^{59}$ Interestingly, this antibody also detected specific pathological proteins in SCA2 and ADCA II, supporting the hypothesis that these too are trinucleotide repeat diseases. Dentatorubropallidoluysian atrophy (DRPLA) is another autosomal dominant disease associated with a trinucleotide repeat, and may present with an ataxic syndrome. ${ }^{6061}$ It is most common in Japan, but is also found in the west. ${ }^{62}$ Although clinical features may overlap with the ADCAs, chorea, myoclonus, epilepsy, or a progressive dementia would favour DRPLA.
ADCA II

Whether using clinical or pathological criteria, ${ }^{163}$ there is general agreement that this ADCA is distinguished from others by the presence of a pigmentary macular dystrophy. Enevoldson and colleagues described 54 members of eight families. ${ }^{64}$ The presenting symptom was ataxia in two thirds of patients and visual failure or both in the remainder. The retinal abnormalities are often subtle. Other neurological features include pyramidal signs and a supranuclear ophthalmoplegia. Onset varied between six months and 60 years with more rapid progression usually seen in early onset cases. Some obligate gene carriers were asymptomatic. Anticipation in the offspring of affected fathers was noted; all infantile onset cases resulted from paternal transmission. Therefore, both clinical and laboratory data support the possibility of the gene mutation being an unstable trinucleotide expansion..$^{59}$

The ADCA type II locus has been mapped to chromosome $3 \mathrm{p} 12-\mathrm{p} 21 \cdot 1$ by three different groups indicating that this phenotype corresponds to a genetically homogenous disease entity. ${ }^{65-67}$

ADCA III

This is described as a relatively benign ADCA with predominant cerebellar features, some pyramidal signs, but no dementia, ocular, or extrapyramidal involvement, with onset over the age of 50 in most patients. The molecular genetic status of this group of ADCAs is unclear. In one study none of 30 ADCA type III families had either the SCA1 or SCA3/MJD mutations suggesting that ADCA III may be genetically distinct, and not just a benign variant of ADCA I. ${ }^{49}$ Ranum et al described a family with a relatively benign ADCA linked to a locus on chromosome 11 (SCA5). ${ }^{58}$ This could be described as ADCA III, although some members had early onset disease with pyramidal features. Late onset ADCA is not uncommon and further molecular genetic characterisation is keenly awaited.

\section{PERIODIC ATAXIA}

Molecular genetic advances have led to the identification of two distinct autosomal dominant disorders characterised by episodic ataxia. In both types the ataxic episodes may be suppressed by acetazolamide. Episodic ataxia type 1 is caused by mutations in the potassium channel gene (KCNA1) on chromosome $12 .{ }^{68}$ Attacks are brief-seconds to minutes - and are precipitated by startle 
and exercise. A clue to this disorder may be the presence of interictal myokymia in the periorbital muscles or hands, responsive to phenytoin.

The cause of episodic ataxia type 2 is not yet defined. Episodes of ataxia may be precipitated by emotional stress and exercise but not by startle. Attacks may last several hours or more, with interictal nystagmus or a progressive cerebellar syndrome. Vahedi et al mapped the gene to chromosome $19 \mathrm{p} .{ }^{69}$ Two other groups have found linkage to the same locus, indicating genetic homogeneity. ${ }^{70} 71$ The same region has been implicated in linkage studies of families with CADASIL (cerebral autosomal dominant arteriopathy with subcortical infarcts and leucoencephalopathy) and familial hemiplegic migraine. Interestingly, all three disorders may manifest with ataxia. A recent study suggests that CADASIL and episodic ataxia type 3 are not allelic, but the relation of these two disorders to familial hemiplegic migraine remains unclear. ${ }^{72}$

\section{Conclusion}

The pace of genetic advances in this decade is startling. After the identification of the molecular genetic basis of ataxias, the next scientific challenge is to understand the normal and aberrant function of the proteins corresponding to the mutated genes. This is already under way. Eventually this will provide the basis for planning rational treatments. However, the clinician can already use the new advances to help patients.

Direct testing for mutations at the SCA1, SCA3/MJD loci is routinely available and testing for the frataxin expansion is now possible. Analysis of the SCA loci in patients with $\mathrm{ADCA}$ allows a precise non-invasive diagnosis (in the minority that have these mutations). In the context of symptomatic patients the physician should obtain consent in the normal manner for any potentially diagnostic procedure. However, testing of presymptomatic subjects in families with known mutations raises complex issues which require full discussion. The situation is similar to that in Huntington's disease, and testing of at risk subjects should follow the Huntington's disease protocol, with pretest and post-test counselling. ${ }^{73}$ The responsible genes at the SCA2, SCA4, and SCA5 loci have not yet been identified. Linkage analysis within families with an adequate family structure is possible, but is not routinely available outside research laboratories.

Several groups have studied patients with sporadic ataxias for the SCA1 and SCA3/MJD mutations. This has been unfruitful. This group of patients will undoubtedly be further investigated as novel SCA mutations are uncovered, but the results to date suggest that such patients do not have SCA mutations causing their disease.

Direct mutation analysis in Friedreich's ataxia will be helpful diagnostically. Unfortunately, the average age of onset of the disease means that most families are complete before the diagnosis is apparent, preventing prenatal testing. Nevertheless, the availability of direct mutation analysis will aid early diagnosis, make prenatal diagnosis more secure, and will help advise relatives of carrier status. The comparative rarity of the disorder will make screening of the general population impracticable in the foreseeable future. I gratefully acknowledge the teaching and inspiration of the late Professor Anita
Harding

Wessex Neurological Centre,

S R HAMMANS

Southampton General Hospital,

Shirley,

Southampton,

SO16 6YD,UK
1 Harding AE. Classification of the hereditary ataxias and paraplegias. Lancet 1983;i:1151-5.

2 Nikali $\mathrm{K}$, Suomalainen A, Terwilliger J, et al. Random search for shared chromosomal regions in four affected individuals: the assignment of a new hereditary ataxia locus. Am $₹$ Hum Genet 1995; 56:1088-95.

3 Friedreich N. Uber Ataxie mit besonderer berücksichtigung der heritären formen. Virchows Arch Pathol Anat Histol 1876;68:145-245.

4 Harding AE. Friedreich's ataxia: a clinical and genetic study of 90 families with an analysis of early diagnostic criteria and intrafamilial clustering of clinical features. Brain 1981;104:589-620

5 Chamberlain S, Shaw J, Rowland A, et al. Mapping of mutation causing Friedreich's ataxia to human chromosome 9. Nature 1988;334:248-50.

6 Duclos F, Rodius F, Wrogeman K, et al. The Friedreich ataxia region characterisation of two novel genes and reduction of the critical region to 300 kb. Hum Mol Genet 1993;3:909-14.

7 Montermini L, Rodius F, Pianese L, et al. The Friedreich ataxia critical region spans a 150-kb interval on chromosome 9q13. Am f Hum Genet 1995;57:1061-7.

8 Carvajal JJ, Pook MA, Doudney K, et al. Friedreich's ataxia: a defect in signal transduction? Hum Mol Genet 1995;4:1411-9.

9 Campuzano V, Montermini L, Moltò MD, et al. Friedreich's ataxia: autosomal recessive disease caused by an intronic GAA triplet repeat expansion. Science 1996;271:1423-7.

10 Geoffroy G, Barbeau A, Breton A, et al. Clinical description and roentgenologic evaluation of patients with Friedreich's ataxia. Can $\mathcal{J}$ Neurol Sci 1976;3:279-86.

11 De Michele G, Filla A, Cavalcanti F, et al. Late onset Friedreich's disease: clinical features and mapping of mutation to the FRDA locus. $\mathcal{f}$ Neurol Neurosurg Psychiatry 1994;57:977-9.

12 Klockgether T, Chamberlain S, Wüllner U, et al. Late-onset Friedreich's ataxia. Molecular genetics, clinical neurophysiology, and magnetic resonance imaging. Arch Neurol 1993;50:803-6.

13 Palau F, De Michele G, Vilcez J, et al. Early-onset ataxia with cardiomyopathy and retained tendon reflexes maps to the Friedreich's ataxia locus on chromosome 9q. Ann Neurol 1995;37:359-62.

14 Klockgether T, Zühlke C, Schulz JB, et al. Friedreich's ataxia with retained tendon reflexes: molecular genetics, clinical neurophysiology, and magnetic resonance imaging. Neurology 1996;46:118-21.

15 Harding AE. Early onset cerebellar ataxia with retained tendon reflexes: clinical and genetic study of a disorder distinct from Friedreich's ataxia. $\mathcal{F}$ Neurol Neurosurg Psychiatry 1981;44:503-8.

16 Filla A, De Michele, Cavalcanti F, et al. Clinical and genetic heterogeneity in early onset cerebellar ataxia with retained reflexes. $\mathcal{f}$ Neurol Neurosur Psychiatry 1990;53:667-70.

17 Wüllner U, Klockgether T, Petersen D, Naegele T, Dichgans J. Magnetic resonance imaging in hereditary and idiopathic ataxia. Neurology 1993; 43:318-25.

18 Burck U, Goebel HH, Kuhlendahl HD, Meier C, Goebel KM. Neuromyopathy and vitamin E deficency in man. Neuropaediatrics 1981; 12:267-78.

19 Belal S, Hentati F, Ben Hamida C, et al. Friedreich's ataxia-Vitamin E responsive type. Clin Neurosci 1995;3:39-42.

20 Ben Hamida C, Doerflinger N, Belal S, et al. Localization of Friedreich ataxia with selective vitamin $\mathrm{E}$ deficiency to chromosome $8 \mathrm{q}$ by homozygosity mapping. Nature Genet 1993;5:195-200.

21 Ouahchi $\mathrm{K}$, Arita $\mathrm{M}$, Kayden $\mathrm{H}$, et al. Ataxia with isolated vitamin $\mathrm{E}$ deficiency is caused by mutations in the $\alpha$-tocopherol transfer protein Nature Genet 1995;9:141-5.

22 Gotoda $\mathrm{T}$, Arita $\mathrm{M}$, Arai $\mathrm{H}$, et al. Adult-onset spinocerebellar dysfunction caused by a mutation in the gene for the $\alpha$-tocopherol-transfer protein. $N$ Engl F Med 1995;333:1313-8.

23 Harding AE. The clinical features and classification of the late onset autosomal dominant cerebellar ataxias: a study of 11 families, including descendants of the "Drew family of Walworth". Brain 1982;105:1-28.

24 Hammans SR, Sweeney MG, Brockington M, et al. The mitochondrial DNA transfer RNALys $A \rightarrow G(8344)$ mutation: clinical phenotype and relationship to proportion of mutant mitochondrial DNA. Brain 1993; 116:617-32.

25 Yakura H, Wasisaka A, Fujimot S, Itakura K. Hereditary ataxia and HLA genotypes $N$ Engl f Med 1974;291:154-5.

26 Jackson JF, Currier RD, Terasaki PI, Morton NE. Spinocerebellar ataxia and HLA linkage: risk prediction by HLA typing. $N$ Engl $f$ Med 1977 296:1138-41

27 Zoghbi HY, Frontali M, Orr HT, et al. Linkage studies in dominantly inherited ataxias. Adv Neurol 1993;23:580-4.

28 Jodice C, Frontali M, Persichetti, et al. The gene for spinal cerebellar ataxia 1 (SCA1) is flanked by two closely linked highly polymorphic microsatellite loci. Hum Mol Genet 1993; 2:959-65.

29 Zoghbi HY, Jodice C, Sandkuijl LA, et al. The gene for autosomal dominant spinocerebellar ataxia (SCA 1) maps telomeric to the HLA complex and is closely linked to the D6S89 in three large kindreds. Am $f$ Hum Genet 1991;49:23-30.

30 Orr HT, Chung M, Banfi S, et al. Expansion of an unstable trinucleotide CAG repeat in spinocerebellar ataxia type 1. Nature Genet 1993;4:221-6.

31 Ranum LPW, Chung M, Banf S, et al. Molecular and clinical correlations in spinocerebellar ataxia type 1 (SCA 1): evidence for familial effects on the age of onset. Am $\mathcal{F}$ Hum Genet 1994;55:244-52.

32 Jodice C, Malaspina P, Persichetti F, et al. Effect of trinucleotide repeat length and parental sex on phenotypic variation in spinocerebellar ataxia 1. Am $\mathcal{F}$ Hum Genet 1994;54:959-65.

33 Dubourg O. Dürr A, Cancel G, et al. Analysis of the SCA1 CAG repeat in a large number of families with dominant ataxia: clinical and molecular correlations Ann Neurol 1995:37:176-80.

34 Klockgether T, Bürk K, Schulz JB, Dichgans J, Wessel K, Auberger G. Absence of SCA1 in idiopathic cerebellar ataxia. I Neurol Neurosurg Psychiatry 1994;57:1439-40.

35 Higgins JJ, Nee LE, Vasconcelos $\mathrm{O}$, et al. Mutations in American families with spinocerebellar ataxia (SCA) type 3: SCA3 is allelic to MachadoJoseph disease. Neurology 1996;46:208-13.

36 Silveira I, Lopes-Cendes I, Kish S, et al. Frequency of spinocerebellar type I, dentatorubropallidoluysiam atrophy, and Machado-Joseph disease in a 1, dentatorubropailidoluysiam atrophy, and Machado-Joseph disease in a

large group of spinocerebellar atrophy patients. Neurology 1996;46:214-8
37 Schöls L, Riess O, Viera-Saecker AMM, et al. Machado-Joseph disease mutations as the genetic basis of most spinocerebellar ataxias in 
Germany. F Neurol Neurosurg Psychiatry 1995;59:449.

38 Giunti $\mathrm{P}$, Sweeney MG, Spadaro M, et al. The trinucleotide repeat expansion on chromosome 6p (SCA1) in autosomal dominant cerebellar ataxias. Brain 1994;117:645-9.

39 Chung M-y, Ranum LPW, Duvick L, Servadio A, Zoghbi HY, Orr HT. Analysis of the CAG repeat expansion in spinocerebellar ataxia type 1: evidence for a possible mechanism predisposing to instability. Nature Genet 1993;5:254-8.

40 Quan F, Janas J, Popovich BW. A novel CAG repeat configuration in the SCAl gene: implications for the molecular diagnostics of spinocerebellar SCA1 gene: implications for the molecular dia

41 Banfi $S$, Servadio A, Chung $M$, et al. Identification and characterization of the gene causing type 1 spinocerebellar ataxia. Nature Genet 1994;7:513-9.

42 Banfi S, Servadio A, Chung M, et al. Cloning and developmental analysis of the murine homolog of the spinocerebellar ataxia type 1 gene (Scal). Hum Mol Genet 1996;5:33-40.

43 Robitaille Y, Schut L, Kish SJ. Structural and immunocytochemical features of olivopontocerebellar atrophy caused by the spinocerebellar ataxia type 1 (SCA-1) mutation define a unique phenotype. Acta Neuropathol 1995;90:572-81.

44 Rosenberg RN. Machado-Joseph disease: an autosomal dominant motor system degeneration [review]. Mov Disord 1992;7:193-203.

45 Takiyama Y, Nishizawa M, Tanaka $\mathrm{H}$, et al. The gene for Machado-Joseph disease maps to chromosome 14q. Nat Genet 1993;4:300-4.

46 Twist EC, Casabon LK, Ruttledge MH, et al. Machado Joseph disease maps to the same region of chromosome 14 as the spinocerebellar ataxia type 3 locus. $₹$ Med Genet 1995;32:25-31.

47 Stevanin G, Cancel G, Dürr A, et al. The gene for spinal cerebellar ataxia 3 (SCA3) is located in a region of $\sim 3 \mathrm{cM}$ on chromosome 14q24.3-q32.2. Am $\mathcal{F}$ Hum Genet 1995;56:193-201.

48 Kawaguchi Y, Okamoto T, Taniwaki M, et al. CAG expansions in a novel gene for Machado-Joseph disease at chromosome 14q32-1. Nat Genet 1994;8:221-8.

49 Giunti P, Sweeney MG, Harding AE. Detection of the Machado-Jospeh disease/spinocerebellar ataxia three trinucleotide repeat in families with autosomal dominant motor disorders, including the Drew family of Walworth. Brain 1995;118:1077-85.

50 Matilla T, McCall A, Subramony SH, Zoghbi HY. Molecular and clinical correlations in spinocerebellar ataxia type 3 and Machado-Joseph discorrelations in spinocerebellar a

51 Maruyama H, Nakamura S, Matsuyama Z, et al. Molecular features of the CAG repeats and clinical manifestations of Machado-Joseph disease. Hum Mol Genet 1995;4:807-12.

52 Takiyama Y, Igarishi S, Rogaeva EA, et al. Evidence for inter-generational instability in the CAG repeat in the MJD1 gene and for conserved haplotypes at flanking markers amongst Japanese and Caucasian subjects with Machado-Joseph disease. Hum Mol Genet 1995;4:1137-46.

53 Sudarsky L, Coutinho P. Machado-Joseph disease. Clin Neurosci 1995;3: 17-22.

54 Dürr A, Stevanin G, Cancel G, et al. Spinocerebellar ataxia 3 and Machado-Joseph disease: clinical, molecular, and neuropathological feaMachado-Joseph disease: clinical,

55 Gispert $S$, Twells $R$, Orozco $G$, et al. Chromosomal assignment of the second locus for autosomal dominant cerebellar ataxia (SCA2) to chromosome 12q23-24·1. Nature Genet 1993;4:295-9.

56 Dürr A, Smasja D, Cancel G, et al. Autosomal dominant cerebellar ataxia type I in Martinique (French West Indies). Clinical and neuropathological analysis of 53 patients from three unrelated SCA2 families. Brain 1995;118:1573-81.

57 Gardner K, Alderson K, Galster B, et al. Autosomal dominant spinocerebellar ataxia: clinical description of a distinct hereditary ataxia and cenetic localisation to chromosome 16 (SCA4) in a Utah kindred [abstract]. Neurology 1994;44(suppl 2).A361.4

58 Ranum LPW, Schut LJ, Lundgren JK, Orr HT, Livingston DM. Spinocerebellar ataxia type 5 in a family descended from the grandSpinocerebelar ataxia type 5 in a family descended from the grandparents of Presid

59 Trottier Y, Lutz Y Stevanin, et al. Polyglutamine expansion as a pathological epitope in Huntington's disease and four dominant cerebellar ataxias. Nature 1995;378:403-6.

60 Koide R, Ikeuchi T, Onodera O, et al. Unstable expansion of CAG repeat in hereditary dentatorubralpallidoluysian atrophy (DRPLA) Nat Genet 1994;6:9-13.

61 Nagafuchi S, Yanagisawa $\mathrm{H}$, Sato $\mathrm{K}$, et al. Dentatorubral and pallidoluysian atrophy, expansion of an unstable CAG trinucleotide on chromosome 12p. Nat Genet 1994;45:14-8.

62 Warner TT, Williams LD, Walker RWH, et al. A clinical and molecular genetic study of dentatorubralpallidoluysian atrophy in four European families. Ann Neurol 1995;37:452-9.

63 Konigsmark BW, Weiner LP. The olivopontocerebellar atrophies: a review. Medicine 1970;49:227-41.

64 Enevoldson TP, Sanders MD, Harding AE. Autosomal dominant cerebellar ataxia with pigmentary macular dystrophy: a clinical and genetic study of eight families. Brain 1994;117:445-60

65 Benomar A, Krols L, Stevanin G, et al. The gene for autosomal dominant cerebellar ataxia with pigmentary macular dystrophy maps to chromosome 3p12-p21·1. Nat Genet 1995;10:84-8.

66 Gouw LG, Kaplan CD, Haines JH, et al. Retinal degeneration characterizes a spinocerebellar ataxia mapping to chromosome 3p. Nat Genet 1995;10:89-93.

67 Holmberg M, Johansson J, Forsgren L, Heijbel J, Sandgren O, Holmgren G. Localization of autosomal dominant cerebellar ataxia associated with Mol Genet 1995;4:1441-5.

68 Browne DL, Gancher ST, Nutt JG, et al. Episodic ataxia/myokymia syndrome is associated with point mutations in the human potassium channel drome is associated with point mutations in the

69 Vahedi $\mathrm{K}$, Outel A, Van Bogaert $\mathrm{P}$, et al. A gene for hereditary paroxysmal cerebellar ataxia maps to chromosome 19p. Ann Neurol 1995;37:289m93.

70 Teh BT, Silburn P, Lindblad K, et al. Familial periodic cerebellar ataxia without myokymia maps to a $19-\mathrm{cM}$.region on $19 \mathrm{p} 13$. Am $\mathcal{F}$ Hum Genet 1995;56:1443-9.

71 Kramer PL, Yue $\mathrm{Q}$ Gancher ST, et al. A locus for the nystagmus-associated form of episodic ataxia maps to an $11-\mathrm{cM}$ region on chromsome 19p. Am ₹ Hum Genet 1995;57:182-185.

72 Ducros A, Nagy T, Alamowitch S, et al. Cerebral autosomal dominant arteriopathy with subcortical infarcts and leukoencephalopathy, genetic homogeneity, and mapping of the locus within a 2-cm interval. $A m$ f Hum Genet 1996;58:171-81.

73 World Federation of Neurology: Research Committee. Research Group on Huntington's disease. Ethical issues policy statement on Huntington's Huntington's disease. Ethical issues policy statement on Huntington's
disease molecular genetics predictive tests. $₹$ Neurol Sci 1989;94:327-32. 